
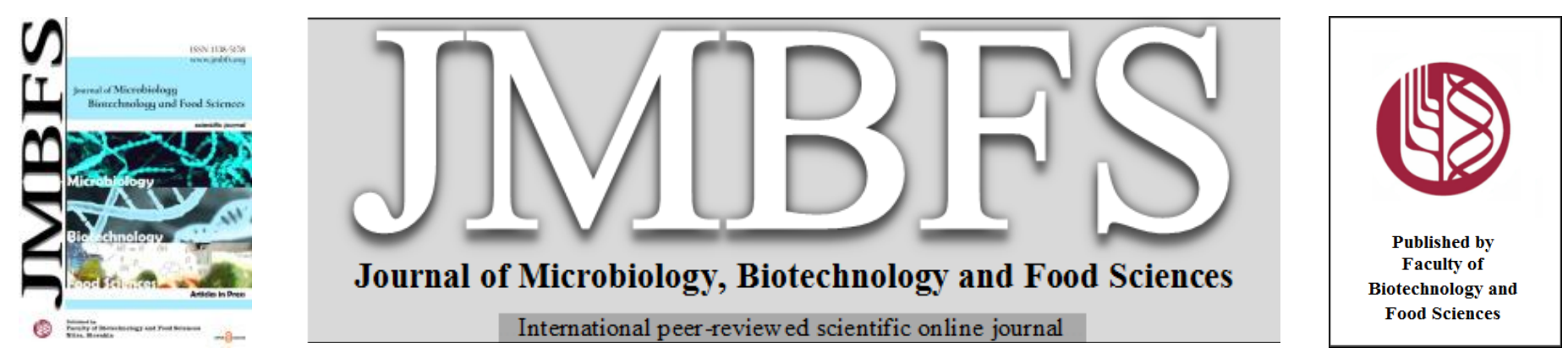

\title{
VALORIZATION OF PERILLALDEHYDE MOLECULE CONTAINED IN THE ESSENTIAL OIL OF Ammodaucus Leucotrichus Coss. FROM THE SAHARAN ZONES OF MOROCCO
}

\author{
Omayma Bouzekri*l, Sabah El Gamouz ${ }^{1}$, Adib Ghaleb ${ }^{2}$, Ali Amechrouq ${ }^{1}$, Mostafa El Idrissi ${ }^{1}$, M'barek Choukrad $^{1}$ \\ Address(es): \\ ${ }^{1}$ Molecular Chemistry and Natural Substances Laboratory, Moulay Ismail University, Faculty of Sciences, B.P. 11201, Zitoune, Meknes, Morocco. \\ ${ }^{2}$ Analytic and Molecular Chemistry "LCAM" laboratory, Cadi Ayyad University, Faculty Polydisciplinary of Safi, Safi 46030 Morocco.
}

*Corresponding author: omayma.bk.ouma@gmail.com

\section{ARTICLE INFO}

Received 10. 2. 2021

Revised 13. 8. 2021

Accepted 2. 9. 2021

Published 1.2. 2022

Regular article OPEN $\partial_{\text {ACCESS }}$

\section{ABSTRACT}

The aim of this work is to valorise the species Ammodaucus leucotrichus Coss which is known by its abundance in perillaldehyde. The plant material was collected from two regions in Morocco: Errachidia and Smara region, then was hydrodistilled. The essential oils (EOs) obtained were firstly characterized by gas chromatography coupled to mass spectrometry (GC-MS). Secondly the EO with the major component is the perillaldehyde was used as starting material to semi-synthesize three $p$-menthane monoterpenoids. The semi-synthesized compounds from perillaldehyde were studied for their docking behavior against Lung Cancer with the crystallographic structure of the kinase domain of EGFR protein using surflex-docking.

The GC/MS analysis of essential oils, showed a total of 25 components accounts $99.51 \%$ for Errachidia's EO while 28 components account for $99.83 \%$ for Smara's EO. GC/MS analysis showed that perillaldehyde is the major components in the EO of Errachidia with a percentage of $74.71 \%$. For this purpose, Errachidia's EO was used to semi-synthesize the perilla alcohol, the perillic acid, and the perillartine. The three compounds were obtained in good yield, their structures were confirmed by GC/MS and Infrared (IR). The molecular docking study showed a good binding affinity between the perilla alcohol $(\mathrm{POH})$ and the lung cancer receptor than perillic acid and perillartine.

The species Ammodaucus leucotrichus Coss. could be considered a promising source of p-menthan monoterpenoids, known for their anticancerous properties.

Keywords: Ammaudocus leucotrichus Coss.; Essential oil; molecular docking; perillaldehyde; Semisynthesis

\section{INTRODUCTION}

Lung cancer is the most fatal type of cancer. The percentage of deaths because of this cancer account for about $19 \%$ of all cancer deaths (Torre et al., 2016). Lung cancer is the leading cause of cancer death in men and the second leading cause of cancer death in women worldwide (Torre et al., 2016). Recently, medical research has given notable attention to natural products in the field of cancer treatment (Prakash et al., 2013). More than two-thirds of the drugs currently used in cancer treatments come directly from natural products (Gurnani et al., 2014). Much recent researches have great interest in screening of medicinal plants for new therapeutics (Bhuyar et al. 2021). Because of their efficacy, safety, and availability (Naczk et $\boldsymbol{a l}$., 2006). The secondary metabolites existed in plants are manly used as active principals of many drags (Bhuyar et al. 2021). Ammodaucus leucotrichus Coss belongs to the apiaceae family and Ammodaucus genus. This species is widespread in Saharan and sub-Saharan countries, and it is known to be endemic to North Africa, specifically Morocco, Algeria, and Tunisia, extending to Egypt and tropical Africa in addition to the Canary Islands (Manssouri et al., 2016). Previous studies on the volatile compounds of Ammodaucus leucotrichus Coss. esseantial oil, have revealed the existence of perillaldehyde among its chemical composition. (Abu Zarga et al., 2013; El-Haci et al., 2014; Manssouri et al., 2020). perillaldehyde is a monoterpenoid with p-menthane structure. Monoterpenoid compounds with p-menthane are known for their antioxidan activity and anticancer potential. Moreover, the compounds with this structure are reported to possess in vitro cytotoxic effects on cancer cell lines (Imamura et al., 2014). The monoterpene perilla alcohol is the most promising member of the group p-menthanes, this compound has attracted attention recently by being a strong candidate for cancer treatment (Yeruva et al., 2007). Perilla alcohol is known for its bioactivity as an antitumor agent and inhibitor of tumor cell growth in various tissues (Imamura et al., 2014). Clinical trials were conducted on the toxicity and chemotherapy effects of Perilla alcohol (Raphael et al., 2003; Yeruva et al., 2007). Another group found that limonene and perillic acid inhibited DNA synthesis and proliferation in PHA-stimulated peripheral blood mononuclear cells and perillic acid inhibited IL- 2 and IL-10 production and secretion in mitogen- activated human T lymphocytes (Swain et al., 2020). As well, Perillartine is considered a monoterpene with antioxidant and radical scavenging activities (Swain et al., 2020).

The objective of this study was a valorization of the species Ammodaucus Leucotrichus Coss., to confirm the potential of this species in the pharmaceutical industry as a source of perillaldehyde. For this purpose, plant material was collected in two Saharan regions in Morocco: (Draa-Tafilalet and Laâyoune-Sakia El Hamra). The chemical composition of the essential oils was analyzed by gas chromatography-mass spectrometry (GC/Ms) analyses with the aim of using the major component in the essential oil which is the perillaldehyde to semi-synthesize bioactive compounds of the $p$-menthane structure which are perilla alcohol (POH), perillic acid and perillartine. As these compounds are known for their anticancer activity, a theoretical study of these compounds against lung cancer, was carried out. The molecular docking behavior of perilla alcohol $(\mathrm{POH})$, perillic acid and perillartine with the crystallographic structure of the kinase domain of the EGFR protein was investigated using surflex-docking.

\section{MATERIAL AND METHODS}

\section{Molecular Docking}

The bioactive compounds Perilla alcohol, Perillic acid and Perillartine are known for their anticancer activity, therefore, the three compounds were used for molecular docking against Lung Cancer. The crystal structure of EGFR kinase domain in complex with Iressa was downloaded from the PDB data bank with PDB entry: 2ITY (Yun et al., 2007) and was used as the initial 3D model to determine the docking-binding models. Surflex-Dock module is performed for molecular docking; the protocol of receptor pocket was established by the ligand based method. 


\section{Protein target preparation}

All water molecules in crystal structures were deleted and the polar hydrogen atoms were added. The IRE ligand (native ligand) of the downloaded structure was retrieved and redocked in the same pocket to determine the performance of this molecular docking study. All studied ligands are docked in the same pockets for further analysis applying an automatic docking. Total scores are expressed in - log $10(K d)$ units, in order to present the binding affinities (Yadav et al., 2018) Surflex-Dock scores represent binding energies; therefore, they determine ligandreceptor interactions.

\section{Ligands preparation}

The chemical structure of all ligands was designed using Sybyl-x 2.0 drawing interface. The conformation of every compound is energetically minimized using Tripos force field and Powell conjugated gradient algorithm with a convergence criterion of $0.05 \mathrm{kcal} / \mathrm{mol}$ and Gasteiger-Huckel charges (Purcell et al., 1967).

\section{Lipinski rule of bioactive compounds Perilla alcohol, Perillic acid and Perillartine}

The main goal to verify Lipinski rule is to obtain a preliminary prediction of the potential pharmacological capacities of a molecule to become a drug. The tree studied compounds were submitted to the calculation of their physicochemical properties such as molecular weight (MW), octanol/water partition coefficient $(\operatorname{LogP})$, number of rotatable bond $\left(\mathrm{N}_{\text {rot }}\right)$ hydrogen bond donor $(\mathrm{HBD})$ and acceptor (HBA) using Swiss ADME webserve (Daina et al., 2017).

\section{The plant material}

The fruits of Ammodaucus leucotrichus Coss. Were collected in April 2018 from two different regions of Morocco: Errachidia (ERR) region: Draa-Tafilalet and Smara (SM) region: Laâyoune-Sakia El Hamra. The geographical coordinates of Errachidia are: $31^{\circ} 07^{\prime} 10^{\prime N}-5^{\circ} 09^{\prime} 58$ "W and those of Smara are: $26^{\circ} 45^{\prime} 32.1$ "N $11^{\circ} 41$ '10.6 "W.

The fruits were dried in the dark, the extraction of essential oils was carried out using the method of hydrodistillation by Clevenger device. $100 \mathrm{~g}$ of fruits was powdered then extracts. The hydrodistillation was repeated three times and the obtained essential oils were dried with anhydrous sodium sulfate and stored at $4{ }^{\circ} \mathrm{C}$ in amber glass flasks until analysis.

\section{Analysis of essential oil by GC/MS}

The constituents of the essential oils were analyzed by the GC-Ms method. GCMs analyses were performed using Thermo Scientific ISQ Series Quadrupole GCMS System. The GC instrument was equipped with a TG-1MS capillary column $(30 \mathrm{~m} \times 0.32 \mathrm{~mm}$ i.d., $0.25 \mu \mathrm{m}$ film thickness). Here the carrier gas used was Helium with a flow rate of $1.5 \mathrm{ml} / \mathrm{min}$ and EI source at $70 \mathrm{eV}$. The GC oven was held at a temperature of $40^{\circ} \mathrm{C}$ at the initial time and programmed to $200^{\circ} \mathrm{C}$ at $4^{\circ} \mathrm{C} / \mathrm{min}$ and up to $300^{\circ} \mathrm{C}$ at $30^{\circ} \mathrm{C} / \mathrm{min}$ and maintained for $10 \mathrm{~min} .1 \mu 1$ of the dilute sample (in cyclohexane $1: 100, \mathrm{v} / \mathrm{v}$ ) was injected with a constant temperature of $250^{\circ} \mathrm{C}$ through a split injector. The identification of chemical components was carried out by the comparison of the Chemical Abstract Service registry number (Cas) and matching their mass spectra value with the corresponding database NIST library and with mass spectral literature (the Reverse Match Factor RSI > 600 ) (Lal et al., 2019b, 2019a,).

Semi-synthesis of Perilla alcohol, Perillic acid and Perillartine from the perillaldehyde

\section{Reduction of perillaldehyde to Perilla alcohol with $\mathrm{NaBH}_{4}$}

In order to reduce carbonyl compounds to their corresponding alcohols, lithium aluminum hydride $\left(\mathrm{LiAlH}_{4}\right)$ or sodium borohydride $\left(\mathrm{NaBH}_{4}\right)$ are frequently used (Setamdideh et al., 2012). In this case, the $\mathrm{NaBH}_{4}$ was used because it is more selective to carbonyl group. In a Three-neck round-bottom flask equipped with a dropping funnel and with nitrogen sparging, 4 equimolar of the aldehyde were added drop-wise to a mixture of $\mathrm{NaBH} 4$ solubilized in diethyl ether and ethanol. The reaction was stirred for $24 \mathrm{~h}$ in ice. After the reaction was complete, $12 \mathrm{~mL}$ of distilled water was added and the mixture was extracted with diethyl ether $(3 \times 20$ $\mathrm{mL}$ ) and dried over anhydrous magnesium sulfate. The diethyl ether was evaporated in a rotary evaporator.

\section{Disproportionation of Perillaldehyde into Perilla alcohol and Perillic acid}

Perillaldehyde (PA) has no alpha hydrogen therefore, cannot be subjected to aldol condensation, but may be disproportionate to an equimolar mixture of primary alcohol and carboxylic salt. The reaction is managed in a strongly basic solution. A concentrated sodium hydroxide solution was prepared in a $100 \mathrm{~mL}$ round-bottom flask adapted with a refrigerant. After dissolution, PA was added to the hot sodium hydroxide solution and agitated until an emulsion was produced. The solution was maintained under reflux during 24 hours. After the reaction was complete, a mixture of $\mathrm{POH}$ and perillic acid sodium salt was obtained. The mixture was transferred into a separating funnel and extracted with diethyl ether $(3 \times 15 \mathrm{~mL})$. The ethereal phases were collected, dried and evaporated and the aqueous phase was acidified with concentrated $\mathrm{HCl}$ to the $\mathrm{pH}$ acid, then stirred with cooling a white precipitate appeared.

\section{Preparation of perillaldehyde oxime}

The synthesis of the aldoxime was done by using a $100 \mathrm{~mL}$ round flask equipped with a refrigerant and dropping funnel. $2.5 \mathrm{~g}$ of Hydroxylammonium chloride $\left[\mathrm{NH}_{3} \mathrm{OH}\right] \mathrm{Cl}, 4 \mathrm{~g}$ of sodium acetate $\mathrm{C}_{2} \mathrm{H}_{3} \mathrm{NaO}_{2}$ and $10 \mathrm{~mL}$ of water were placed in the round flask, the mixture was stirred until dissolution, then the solution was heated $\left(40^{\circ} \mathrm{C}\right) 2.5 \mathrm{~mL}$ of PA was wise dropped, after the appearance of the oxime it was filtered then washed with ice water.

\section{RESULTS AND DISCUSSION}

\section{Molecular Docking}

The compounds Perilla alcohol (POH), Perillic acid, and Perillartine which are known for their lung cancer inhibition (Yeruva et al., 2007) were studied for their docking behavior with the crystallographic structure of the kinase domain of EGFR protein retrieved from the Protein Databank repository (www.rcsb.org/pdb; ID: 2ITY) using surflex-docking. The stable conformation of Perilla alcohol (POH) compound shows better binding affinity than Perillic acid and Perillartine with a scoring of 4.18, 3.80 and 3.56 respectively (see Table 1 ).

Table 1 Summery of affinities and type's interactions between studied compounds and lung cancer receptor

\begin{tabular}{|c|c|c|c|}
\hline $\begin{array}{c}\text { Stable } \\
\text { conformation of } \\
\text { compound }\end{array}$ & Score & $\begin{array}{c}\text { Hydrogen } \\
\text { Interactions } \\
\text { with residue(s) } \\
\end{array}$ & $\begin{array}{l}\text { Alkyl Interactions with } \\
\text { residue(s) }\end{array}$ \\
\hline Perilla alcohol & 4.18 & PRO A:794 & $\begin{array}{c}\text { LEU A :718; LEU A :844; } \\
\text { ALA A : 743; } \\
\text { VAL A:726; LEU A:792 } \\
\end{array}$ \\
\hline Perillic acid & 3.80 & $\begin{array}{c}\text { MET:793; GLN } \\
\text { A:791 }\end{array}$ & $\begin{array}{c}\text { LEU A: 718; CYS A: 797; } \\
\text { ALA A: 743; } \\
\text { LEU A: } 844 \\
\end{array}$ \\
\hline Perillartine & 3.56 & Lys A: 745 & $\begin{array}{l}\text { VAL A:726; LEU A:718; LEU } \\
\text { A: 792; } \\
\text { LEU A : 844 ; ALA A : 743; } \\
\text { MET : } 793\end{array}$ \\
\hline
\end{tabular}

Hydrogen bonding is one of the significant factors to determine the stability of protein-ligand bonding. The compound Perilla alcohol (POH) is stabilized by hydrogen bond interaction between hydroxyl group and PRO A:794 residue, and by alkyl interactions with LEU A:718; LEU A:844; ALA A:743; VAL A:726; LEU A:792 residues. The green and brown contours around hydroxyl group indicate the hydrophobicity and hydrogen bond characters of receptor that stabilize Ligandreceptor complex, therefore the inhibition ability (see Figure 1). The Perillic acid forms two hydrogen bonds with MET :793 and GLN A:791 residues, also alkyl interactions with LEU A: 718; CYS A: 797; ALA A: 743 and LEU A: 844 residues (see Figure 2). The Perillartine forms a hydrogen bond with Lys A: 745 residue and alkyl interactions with VAL A: 726; LEU A:718; LEU A: 792; LEU A: 844; ALA A: 743; MET: 793 residues (see Figure 3). The brown color around the compounds shows the hydrophobic character of amino acids and the green color indicate the important of hydrogen bond interaction to stabilize the affinity of the complex.

\section{Drug-likeness Lipinski’s rule}

Depending on lipinski's rule compounds with more than 5 hydrogen bond donor 10 hydrogen bond acceptor, molecular weight (MW) over than $500 \mathrm{Da}$ and LogP more than 5, are poor absorbed drugs (Lipinski et al., 2001). The in silico results of the three bioactive compounds, indicate that all compounds have $\log \mathrm{P}$ value under 5 , and their molecular weight less than $500 \mathrm{Da}$ with hydrogen bond donor and acceptor less than five with two rotatable bonds (see Table 2), which is in agreement with lipinski's rule therefore indicate a good oral bioavailability.

Table 2 Physicochemical parameters of the three synthesized compounds

\begin{tabular}{cccccc}
\hline Compound & $\log \mathrm{P}$ & MW & HBD & HBA & $\mathbf{N}_{\text {rotb }}$ \\
\hline Perilla alcohol & 2.5 & 152.23 & 1 & 1 & 2 \\
\hline Perillic acid & 2 & 166.22 & 1 & 2 & 2 \\
\hline Perillartine & 2.32 & 165.23 & 1 & 2 & 2 \\
\hline
\end{tabular}




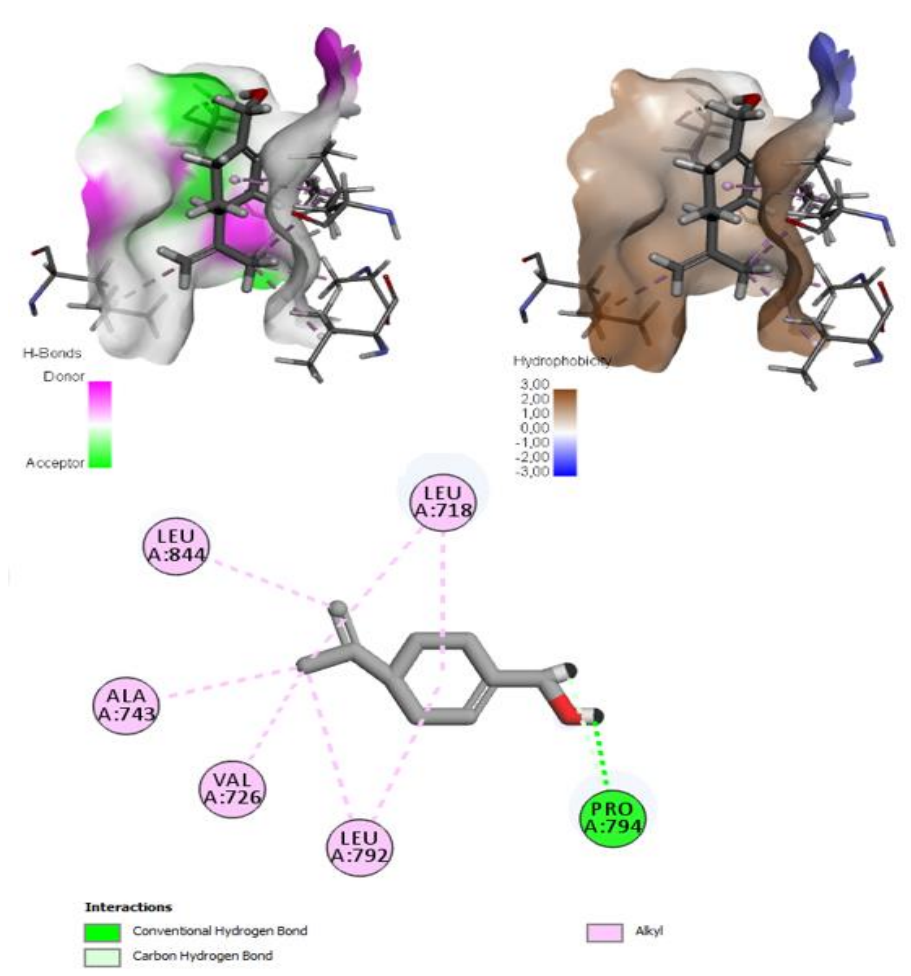

Figure 1 The interactions between compound Perilla alcohol (POH) and PDB:2ITY receptor
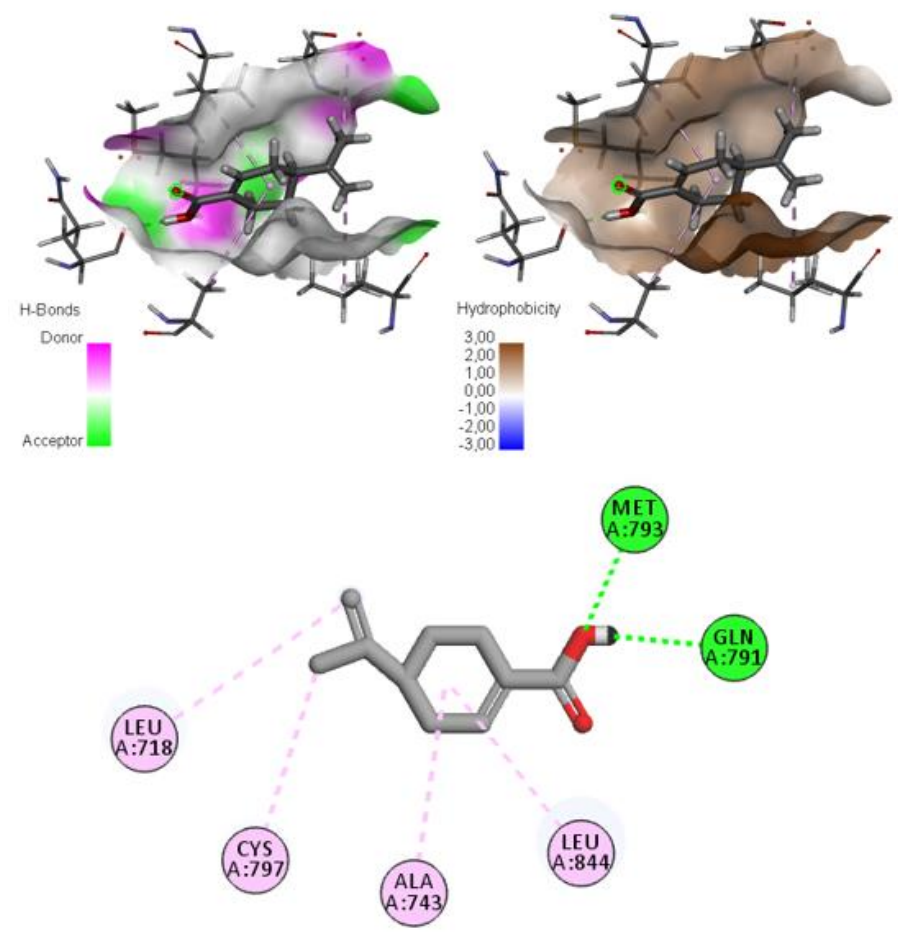

Interactions

Conventonal Hydrogen Bond

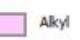

Figure 2 The interactions between compound Perillic acid and PDB:2ITY receptor
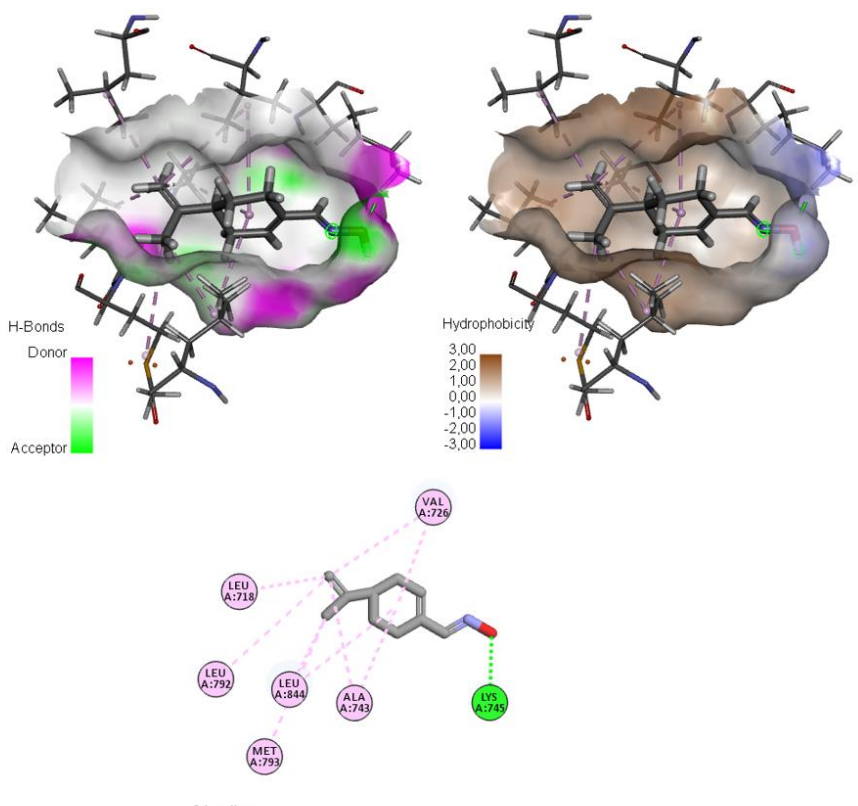

Figure 3 The interactions between compound Perillartine and PDB:2ITY receptor

\section{Analysis of essential oil by GC/MS}

The hydro-distillation of Ammodaucus leucotrichus fruits from both ERR and SMR regions yielded a liquid blue oil with a characteristic odor. The EO of Ammodaucus leucotrichus fruits from ERR region recorded the highest yield of $4.26 \mathrm{~g}$; on the other hand, the fruits from SMR region recorded a yield of $3.87 \mathrm{~g}$. The results of GC-Ms analysis of the two essential oils are presented in Table 3.The Retention Indices indicated in the table was determined based on the GC/Ms and literature surveys (Babushok et al., 2011). The EO from ERR contains a total of 25 components and accounts for $99.51 \%$, essentially the oxygenated monoterpenoids and the monoterpenoids hydrocarbons, whereas the total identified components of the EO from SMR was 28 components which accounts for $99.83 \%$. Similarly, to the EO from ERR, mainly the monoterpenoids were identified; the percentage of the monoterpenoids hydrocarbons was higher followed by the oxygenated monoterpenoids. In both oils the sesquiterpenoids and the oxygenated monoterpenoids were identified but in lesser amounts. The major components were Perillaldehyde, D-limonene, $\alpha$-Pinene, $\beta$-Pinene, Methyl perillate, 3-Carene, $\beta$-Myrcene and Perilla alcohol. Comparing their percentages, although the percentage of perillaldehyde and Perilla alcohol in the EO of ERR was higher than the EO of SMR, the percentages of $\alpha$-Pinene, $\beta$-Pinene, Methyl perillate, 3 -Carene and $\beta$ Myrcene, were higher in the EO of SMR. There are 8 components in the EO of ERR that were not present in the EO of SMR which account for $0.49 \%$. There were 10 components with a percentage of $0.46 \%$ missing in the EO of ERR, and 17 components were identified in both EOs. Different factors may be responsible for this quantitative difference including the difference in environmental factors (Gogoi et al., 2018) the climate, the soil nature, and the period of vegetative cycle (Noudjou et al., 2007).

Semi-synthesis of Perilla alcohol, Perillic acid and Perillartine from the Perillaldehyde

According to the chemical components of Ammodaucus leucotrichus essential oil from the two regions, the percentage of perillaldehyde in the

EO from ERR was $74.71 \%$. This high percentage was exploited to hemi-synthesis another bioactive component.

The reduction of perillaldehyde with $\mathrm{NaBH}_{4}$ gave an oily liquid, with a green color and characteristic odor after the evaporation of the diethyl ether. With a yield of $97.64 \%$, the essential oil was analyzed by IR before and after reduction (see figure 4) according to the spectrum a total disappearance of the $\mathrm{CO}$ band of carbonyl was observed around $1678 \mathrm{~cm}^{-1}$ and the appearance of the $\mathrm{OH}$ band of alcohol around $3396 \mathrm{~cm}^{-1}$. The obtained EO was also analyzed by GC-Ms. The comparison of the mass spectra obtained for the sample and those of the built-in libraries NIST, showed the match of the samples chromatogram with Perilla alcohol chromatogram (a) (see figure 5). 
Table 3 GC-MS analysis of Chemical composition of Ammodaucus leucotrichus Coss. \& Dur. essential oils.

$\begin{array}{llllll}\text { Sr No. } & \text { Components } & \text { RT } & \text { RI(DIMS) } & \text { Percentage area of } & \text { Percentage area }\end{array}$

\begin{tabular}{|c|c|c|c|c|c|}
\hline & & & & the EO from ERR \% & EO from SMR \% \\
\hline 1 & $\alpha$-Pinene & 7.83 & 934.5 & 1.68 & 2.40 \\
\hline 2 & Camphene & 8.21 & 947.4 & 0.14 & 0.20 \\
\hline 3 & $\beta$-Pinene & 9.15 & 973.1 & 0.78 & 2.20 \\
\hline 4 & $\beta$-Myrcene & 9.87 & 983.1 & 0.30 & 0.56 \\
\hline 5 & $\alpha$-Phellandrene & 10.18 & 999.1 & 0.10 & 0.20 \\
\hline 6 & 3-Carene & 10.46 & 1007.2 & 1.01 & 2.16 \\
\hline 7 & o-Cymene & 10.76 & 1032 & 0.06 & 0.04 \\
\hline 8 & D-Limonene & 11.16 & 1023.7 & 17.57 & 29.78 \\
\hline 9 & Terpinolene & 13.19 & 1079.3 & & 0.05 \\
\hline 10 & trans-p-Mentha-2,8-dienol & 14.06 & 1107.0 & 0.05 & \\
\hline 11 & cis- Limonene oxide & 14.48 & 1117.9 & 0.02 & $\overline{-}$ \\
\hline 12 & trans- Limonene oxide, & 14.64 & 1122.7 & 0.04 & \\
\hline 13 & trans-Verbenol & 14.93 & 1133.7 & 0.03 & 0.03 \\
\hline 14 & Verbenone & 16.68 & 1184.4 & & 0.02 \\
\hline 15 & Isopiperitenol B & 16.76 & _ & 0.03 & - \\
\hline 16 & L-Perillaldehyde & 17.34 & & 0.21 & \\
\hline 17 & Cumic aldehyde & 17.79 & 1212.6 & 0.22 & 0.12 \\
\hline 18 & 3-Caren-10-al & 18.56 & 1170.8 & 0.07 & \\
\hline 19 & Myrtenal & 18.57 & 1170.8 & & 0.04 \\
\hline 20 & Perrilla aldehyde & 19.14 & 1252.1 & 74.71 & 58.84 \\
\hline 21 & Bornyl acetate & 19.81 & 1270.2 & 0.06 & 0.09 \\
\hline 22 & Perilla alcohol & 20.10 & 1282.1 & 0.62 & 0.53 \\
\hline 23 & Methyl perillate & 23.10 & & 1.48 & 1.56 \\
\hline 24 & $\beta$-Copaene & 23.49 & 1427.3 & - & 0.04 \\
\hline 25 & Caryophyllene & 24.31 & 1419.3 & & 0.02 \\
\hline 26 & $\gamma$-Decalactone & 24.83 & 1426.9 & 0.17 & 0.12 \\
\hline 27 & $\beta$-Copaene & 26.10 & 1427.3 & & 0.06 \\
\hline 28 & Curcumene & 26.16 & 1471.4 & 0.02 & \\
\hline 29 & Bicyclogermacrene & 26.57 & 1489.8 & _ & 0.08 \\
\hline 30 & $\beta$-Cadinene & 27.40 & 1513.9 & & 0.04 \\
\hline 31 & D-Germacren-4-ol & 28.72 & 1568.3 & $\ldots$ & 0.03 \\
\hline 32 & R-Turmerone & 30.87 & & 0.05 & \\
\hline 33 & $\alpha$-Cadinol & 30.79 & 1640.2 & & 0.08 \\
\hline 34 & Shyobunol & 31.72 & 1592.8 & 0.05 & 0.46 \\
\hline 35 & Chamazulene & 32.51 & 1710.0 & 0.04 & 0.08 \\
\hline \multicolumn{4}{|c|}{ The total identified components } & 99.51 & 99.83 \\
\hline \multicolumn{4}{|c|}{ Monoterpenoids hydrocarbons } & 21.68 & 37.67 \\
\hline \multicolumn{4}{|c|}{ Oxygenated monoterpenoids } & 77.71 & 61.35 \\
\hline \multirow{2}{*}{\multicolumn{4}{|c|}{$\begin{array}{l}\text { Sesquiterpenoids hydrocarbons } \\
\text { Sesquiterpenoids monoterpenoids }\end{array}$}} & 0.02 & 0.24 \\
\hline & & & & 0.1 & 0.57 \\
\hline
\end{tabular}

chromatography-mass spectroscopy. RT = Retention time. RI= retention indices in DIMS — dimethylsilicone as Stationary phase.

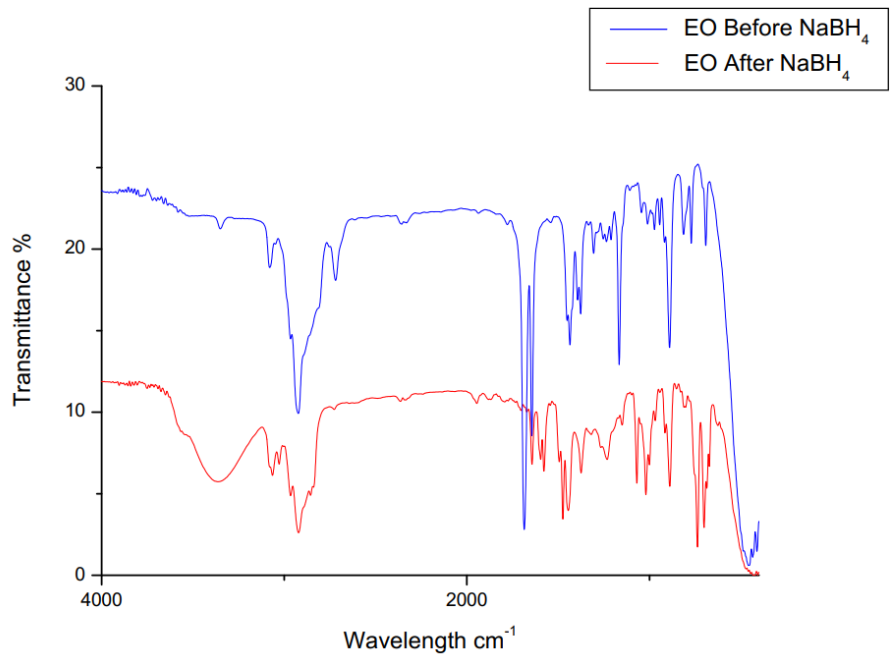

Figure 4 The IR spectra of the hemisynthetic perilla alcohol (a)

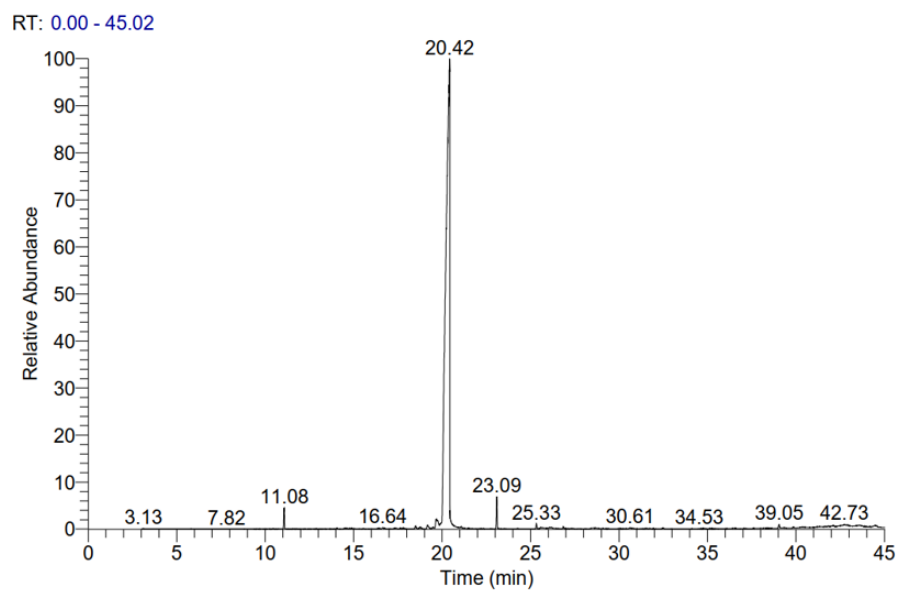

Figure 5 The chromatogram of the hemisynthetic perilla alcohol (a)

Table 4 GC-MS analysis of EO after reduction with $\mathrm{NaBH}_{4}$.

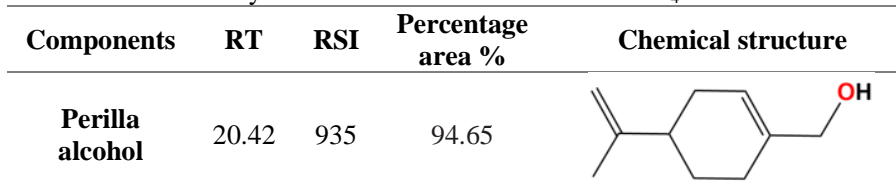

GC-MS = Gas chromatography-mass spectroscopy. RT = Retention time. RSI The Reverse Match Factor (RSI > 600) 
The disproportionation of Perillaldehyde reaction was done in a strongly basic solution. A white precipitate was obtained and the solid was washed with Hexane and diethyl ether to remove the impurities. The yield was $42.85 \%$. The m.p was confirmed $\left(60^{\circ} \mathrm{C}\right)$ then analyzed by IR: $3400,2917,2842,1692,1417$ et $1229 \mathrm{~cm}$ ${ }^{1}$ (see figure 6). according to the spectrum the strong broad band around $3300 \mathrm{~cm}^{-1}$ correspond to $\mathrm{OH}$-stretching of carboxylic acid and the strong band around 1692 $\mathrm{cm}^{-1}$ correspond to $\mathrm{CO}$ stretching of carboxylic acid and the medium band around $1417 \mathrm{~cm}^{-1}$ correspond to $\mathrm{OH}$-bending.

The obtained product was analyzed also by GC-Ms. The comparison of the mass spectra obtained for the sample and those of the built-in libraries NIST, showed the match of the samples chromatogram with the perillic acid chromatogram (b) (see figure 7).

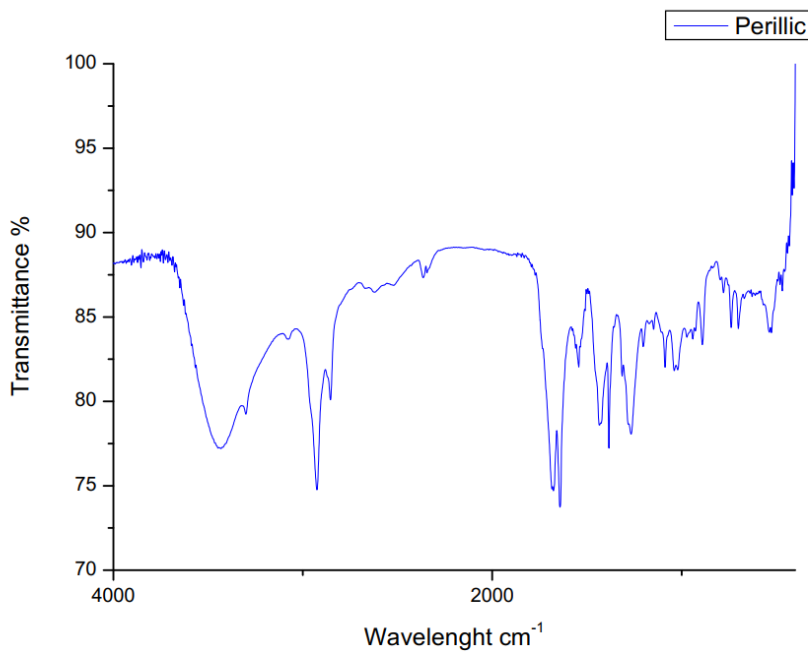

Figure 6 The IR spectra of the hemisynthetic perillic acid (b)

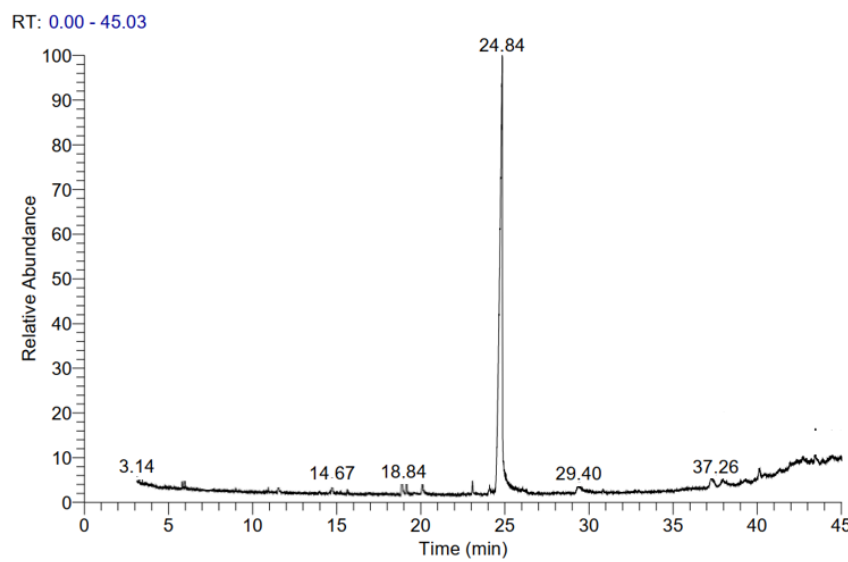

Figure 7 The chromatogram of the hemisynthetic perillic acid (b)

Table 5 GC-MS analysis of Perillic acid.

\begin{tabular}{lcccc}
\hline Components & RT & RSI & $\begin{array}{c}\text { Percentage } \\
\text { area \% }\end{array}$ \\
Perillic acid & 24.85 & 927 & 71.2
\end{tabular}

GC-MS = Gas chromatography-mass spectroscopy. $\mathrm{RT}=$ Retention time. RSI: The Reverse Match Factor (RSI > 600).

The reaction of perillaldehyde oxime offered a white solid with a yield of $92.85 \%$ that was purified. The purity of recrystallized oxime has been confirmed by the melt point and the IR spectra and the physical data of Perillartine (c): m.p $102^{\circ} \mathrm{C}$. IR: $3427,2917,2361,1643,630 \mathrm{~cm}^{-1}$ (see figure 8 ). according to the spectrum the strong broad band around $3400 \mathrm{~cm}^{-1}$ correspond to $\mathrm{OH}$-stretching of oxime and the medium band around $1643 \mathrm{~cm}^{-1}$ correspond to $\mathrm{CN}$-stretching of oxime.

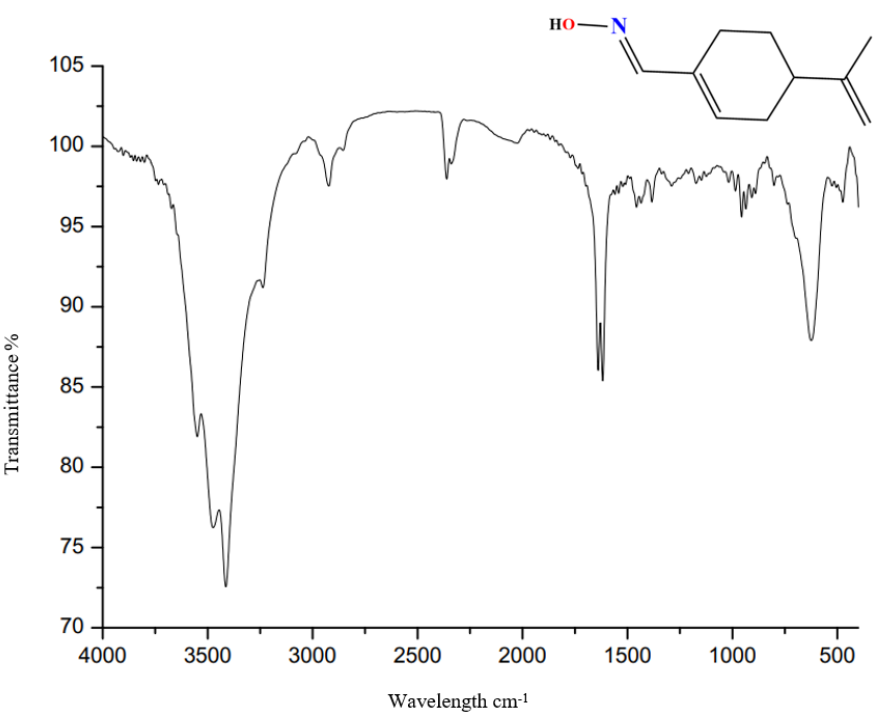

Figure 8 the IR spectra of the hemisynthetic perillartine (c)

\section{CONCLUSION}

The molecular docking study of the three compounds Perilla alcohol, perillic acid, and perillartine has shown significant anticancer activity against lung cancer. Considering their good binding affinities with lung cancer receptors and their good oral bioavailability as good absorbed drugs according to Lipinski's rule. Therefore, those compounds could be used in the pharmaceutical industries against lung cancer.

The objective of the comparative study on the chemical composition of Ammodaucus leucotrichus Coss, essential oils from two regions in Morocco Errachidia and Smara, was to determine which essential oil could be exploited in the medicinal and pharmaceutical industry as a potent source of perillaldehyde. The results of this study showed that the essential oil from the Errachidia region was obtained with a higher yield of $4.26 \%$ and GC-Ms analysis of both essential reveals that the EO from the Errachidia region is very abundant in perillaldehyde with a percentage of $74.71 \%$. The semisynthetic compounds perilla alcohol, perillic acid, and perillartine were obtained with good yields. Therefore, using semi-synthesis instead of bioconversion is more rentable.

At the end of this study, Ammodaucus leucotrichus essential oil can be recommended as valuable starting material leading to active molecules with anticancer and properties and exploited in the medicinal industry.

Acknowledgments: Teacher Laura Santi from the American Language Center Meknes in Morocco for the language editing.

The common analysis center of the faculty of sciences Meknes in Morocco.

Conflict of interests: We wish to confirm that there are no known conflicts of interest associated with this publication and there has been no significant financial support for this work that could have influenced its outcome.

\section{REFERENCES}

Abu Zarga, M.H., Al-Jaber, H.I., Baba Amer, Z.Y., Sakhrib, L., Al-Qudah, M.A., Al-humaidi, J.Y.G., Abaza, I.F., Afifi, F.U., (2013). Chemical Composition, Antimicrobial and Antitumor Activities of Essential Oil of Ammodaucus leucotrichus Growing in Algeria. Journal of Biologically Active Products from Nature. from Nat. 3, 224-231. https://doi.org/10.1080/22311866.2013.833469.

Babushok, V.I., Linstrom, P.J., Zenkevich, I.G., 2011. Retention Indices for Frequently Reported Compounds of Plant Essential Oils. J. Phys. Chem. Ref. Data 40. https://doi.org/10.1063/1.3653552

Bhuyar, P., Rahim, M. H. A., Maniam, G. P., \& Govindan, N. (2021). Isolation and characterization of bioactive compounds in medicinal plant centella asiatica and study the effects on fungal activities. Journal of Microbiology,Biotechnology and Food Sciences, 10 (4), 631-635 https://doi.org/10.15414/jmbfs.2021.10.4.631$\underline{635}$

C.A. Lipinski, F. Lombardo, B.W. Dominy, P.J. Feeney, Adv. Drug Deliv. Rev. 2001. 46.

Daina, A., Michielin, O., Zoete, V., (2017). SwissADME: A free web tool to evaluate pharmacokinetics, drug-likeness and medicinal chemistry friendliness of small molecules. Scientific Reports. 7, 1-13. https://doi.org/10.1038/srep42717.

El-Haci, I.A., Bekhechi, C., Atik-Bekkara, F., Mazari, W., Gherib, M., Bighelli, A., Casanova, J., Tomi, F., (2014). Antimicrobial activity of Ammodaucus 
leucotrichus fruit oil from Algerian Sahara. Natural Product Communications. 9 711-712. https://doi.org/10.1177/1934578x1400900533.

Gogoi, R., Loying, R., Sarma, N., Munda, S., Kumar, S., (2018). Industrial Crops \& Products A comparative study on antioxidant, anti-in fl ammatory, genotoxicity , anti- microbial activities and chemical composition of fruit and leaf essential oils of Litsea cubeba Pers from North-east India. Industrial Crops \& Products journal. 125, 131-139. https://doi.org/10.1016/j.indcrop.2018.08.052.

Gurnani, N., Mehta, D., Gupta, M., Mehta, B.K., (2014). Natural Products : Source of Potential Drugs Natural Products Lab , African Journal of Basic \& Applied Sciences, 6, 171-186. https://doi.org/10.5829/idosi.ajbas.2014.6.6.21983.

Imamura, M., Sasaki, O., Okunishi, K., Nakagome, K., Harada, H., Kawahata, K. Tanaka, R., Yamamoto, K., Dohi, M., (2014). Perillyl alcohol suppresses antigeninduced immune responses in the lung. Biochemical and Biophysical Research Communications. 443, 266-271. https://doi.org/10.1016/j.bbrc.2013.11.106.

Lal, M., Borah, A., Pandey, S.K., (2019)a. Identification of a New High Geraniol Rich Variety "Jor Lab L-15" of Lemongrass [Cymbopogon khasianus (Hack) Stapf (ex Bor)]. Journal of Essential Oil Bearing Plants. TEOP 22 (4) 972 - 978. https://doi.org/10.1080/0972060X.2019.1661797

Lal, M., Dutta, S., Munda, S., Pandey, S.K., (2019)b. Identification and Registration of a High Essential Oil Yielding Variety ( Jor Lab L-14 ) of Lemongrass ( Cymbopogon flexuosus L .) Through Mutation Breeding Technique. Journal of Essential Oil Bearing Plants TEOP 21 (6) 2018 pp 1604 - 1611. https://doi.org/10.1080/0972060X.2018.1559105.

Manssouri, M., Znini, M., El Harrak, A., Majidi, L., (2016). Antifungal activity of essential oil from the fruits of Ammodaucus leucotrichus Coss. \& Dur., in liquid and vapour phase against postharvest phytopathogenic fungi in apples. Journal of Applied Pharmaceutical Science Vol.. 6, 131-136 https://doi.org/10.7324/JAPS.2016.60520.

Manssouri, M., Znini, M., Majidi, L., (2020). Studies on the antioxidant activity of essential oil and various extracts of Ammodaucus leucotrichus Coss. \& Dur. Fruits from Morocco Journal of Taibah University for Science. 14, 124-130. https://doi.org/10.1080/16583655.2019.1710394.

Naczk, M., Shahidi, F., (2006). Phenolics in cereals, fruits and vegetables: Occurrence, extraction and analysis. Journal of Pharmaceutical and Biomedical Analysis. 41, 1523-1542. https://doi.org/10.1016/j.jpba.2006.04.002.

Noudjou, F., Kouninki, H., Ngamo, L.S.T., Maponmestsem, P.M., Ngassoum, M. Hance, T., Haubruge, E., Malaisse, F., Marlier, M., Lognay, G.C.,( 2007). Effect of site location and collecting period on the chemical composition of hyptis spicigera lam. An insecticidal essential oil from north-Cameroon. J. Essent. Oil Res. 19, 597-601. https://doi.org/10.1080/10412905.2007.9699340

Prakash, O., Kumar, A., Kumar, P., Ajeet, A., (2013). Anticancer Potential of Plants and Natural Products: A Review. American Journal of Pharmacological Sciences Vol. 1, No. 6, 104-115. https://doi.org/10.12691/ajps-1-6-1.

Purcell WP, Singer JA. (1967) A brief review and table of semiempirical parameters used in the Hueckel molecular orbital method. $J$ Chem Eng Data;12(2):235-46. https://doi:10.1021/je60033a020.

Setamdideh, D., Rafigh, M., (2012). Reduction of carbonyl compounds to their corresponding alcohols by (Nicotine) (tetrahydroborato)zinc complex as a new stable and efficient reducing agent. E-Journal Chem. 9, 2338-2345. https://doi.org/10.1155/2012/391643.

Swain, S.K., Chandra Dash, U., Kanhar, S., Sahoo, A.K., (2020). Ameliorative effects of Hydrolea zeylanica in streptozotocin-induced oxidative stress and metabolic changes in diabetic rats. J. Ethnopharmacol. 247, 112257. https://doi.org/10.1016/j.jep.2019.112257.

Torre, L.A., Siegel, R.L., Jemal, A., (2016). Lung cancer statistics. Advances in Experimental Medicine and Biology 893, 1-19. https://doi.org/10.1007/978-3319-24223-1_1.

T. J. Raphael and G. Kuttan, (2003). Immunomodulatory Activity of Naturally Occurring Monoterpenes Carvone, Limonene, and Perillic Acid Immunopharmacology and immunotoxicology Vol. 25, No. 2, pp. 285-294, https://doi.org/10.1081/IPH-120020476.

Yadav, D.K., Kumar, S., Saloni, Misra, S., Yadav, L., Teli, M., Sharma, P., Chaudhary, S., Kumar, N., Choi, E.H., Kim, H.S., Kim, M.H., (2018). Molecular Insights into the Interaction of RONS and Thieno[3,2-c]pyran Analogs with SIRT6/COX-2: A Molecular Dynamics Study. Scientific Reports . 8, 1-16. https://doi.org/10.1038/s41598-018-22972-9.

Yeruva, L., Pierre, K.J., Elegbede, A., Wang, R.C., Carper, S.W., (2007). Perillyl alcohol and perillic acid induced cell cycle arrest and apoptosis in non small cell lung cancer cells. Cancer Letters $257 \quad 216-226$ https://doi.org/10.1016/j.canlet.2007.07.020.

Yun, C.H., Boggon, T.J., Li, Y., Woo, M.S., Greulich, H., Meyerson, M., Eck, M.J., (2007). Structures of Lung Cancer-Derived EGFR Mutants and Inhibitor Complexes: Mechanism of Activation and Insights into Differential Inhibitor Sensitivity. Cancer Cell 11, 217-227. https://doi.org/10.1016/j.ccr.2006.12.017. 